\title{
MRS International Materials Research Conference to Be Held in China in June 2008 \\ www.mrs.org/meetings
}

The Materials Research Society (MRS) and Chinese Materials Research Society (C-MRS) announce a joint international conference and exhibit-MRS International Materials Research Conference-to be held in Chongqing, China on June 9-12, 2008

The technical program covers topics on Eco/Environmental Materials, Sustainable Energy Materials, Electronic Packaging Materials, Electronic Materials, Materials and Processes for Flat-Panel Displays, Functional Ceramics, Transportation Materials, Magnesium (co-sponsored by TMS), and Biomaterials for Medical Applications.

Keynote speakers are Alan J. Heeger (University of California, Santa Barbara), presenting a talk on "Bulk Heterojunction Material-Self-Assembled Nanomaterials for Low-Cost Solar Cells"; Jeffrey Holmes (SOM), presenting a talk on "Advanced Materials in Architecture"; and Wan Gang, China's 2007 Minister of Science and Technology and Vice Chair of the China Zhj Gong Party.

The conference is chaired by Paul C.W. Chu (Hong Kong University of Science and Technology, China and University of Houston, USA), Eric Garfunkel (Rutgers University, USA), Sung-su Han (LG Electronics Institute of Technology, Korea), and Huang Boyun (Central South University, China).

A satellite meeting on Advanced Technologies for Advanced Characteri- zations of Advanced Materials will be held in Beijing immediately following the International Materials Research Conference. Meeting dates are June 15-18, 2008. MRS and C-MRS endorse this meeting. The Satellite Meeting will provide a forum for researchers and scientists in the fields of advanced materials and advanced technologies to discuss their latest research results, exchange ideas, and promote interdisciplinary research. Furthermore, the Satellite Meeting will work to enhance and intensify constructive collaborations between Chinese and international scientists.

For more information on both conferences, access Web site www.mrs.org/ meetings. 